\title{
Caldas, matematización de la naturaleza y sentimiento telúrico
}

Con motivo de conmemorarse en el próximo mes de octubre el bicentenario de la muerte de Francisco José de Caldas (1768-1816), la Academia Colombiana de Ciencias Exactas, Físicas y Naturales ha venido adelantando desde el año pasado, en conjunto con universidades, bibliotecas, museos y otras instituciones académicas y científicas, distintas actividades tendientes a recordar aspectos de la vida y la obra del personaje histórico que sin duda alguna más contibuyó a la promoción de la cultura científica en los primeros momentos de instauración de nuestra República. A estas actividades se suma ahora la Revista de la Academia Colombiana de Ciencias Exactas Físicas y Naturales al dedicar a la figura de Caldas el diseño de las portadas de los números publicados en el volumen 40 de este año.

Entre todos sus méritos, la posteridad le ha reconocido a Caldas la capacidad y el talento con los cuales adelantó sus mediciones y cálculos en la Nueva Granada. En este campo Caldas se destacó por aprovechar al máximo libros e instrumentos que él mismo se supo proporcionar después de ingentes dificultades. Humboldt se encuentra entre quienes más contribuyeron a proyectar esta imagen de Caldas. A su llegada a estas regiones de los Andes, Humboldt percibió el genio de Caldas y lo relacionó con el sentimiento telúrico que alentaba la preocupación de los eruditos criollos por el conocimiento del entorno natural y para ello aprovechó las observaciones científicas legadas por los expedicionarios europeos. Estas ideas se encuentran en el más conocido de los elogios de Humboldt a Caldas, en carta enviada a Mutis a su paso por Popayán el 10 de noviembre de 1801 (Hernández de Alba, 1983).

Poco después Caldas tendrá la oportunidad de conocer esta opinión de Humboldt cuando el prusiano le muestra algunos de los apartes de su diario en el encuentro que tienen en Quito. Caldas lo transcribe, lo traduce del original en francés y, por supuesto, lo divulga ampliamente a través de su red de amigos y corresponsales. Este es el texto según la versión francesa transcrita por el mismo Caldas (Carta a Mutis del 6 de abril de 1802, ver: (Caldas, 1978); comparar con la traducción castellana en p.151):

"Este Caldas es un prodigio en astronomía. Nacido en las tinieblas de Popayán y sin haber ido nunca más allá de Santafé, ha construido barómetros, un sector, un cuarto de ciclo en madera. Mide meridianos y latitudes mediante gnomones de 12 a 15 pies. ¡Qué no habría hecho este joven hombre en un país con más medios, en donde no hay que aprender todo por sí mismo! Las obras de Bouguer y de La Condamine han tenido una influencia singular sobre los americanos de Quito a Popayán. El territorio (sol) de este país ha llegado a ser clásico y podría decirse que esto tiene que ver con una característica telúrica (sol natal)."

En este texto de legitimación del talento científico de Caldas como miembro destacado de la élite científica criolla, Humboldt señala dos características de la práctica de esta misma élite a comienzos del siglo XIX. En primer, lugar la naturaleza peculiar de la empresa científica en las periferias dado su alejamiento de los centros metropolitanos. Si ser autodidacta era el recurso para superar las precariedades de la formación en las instituciones educativas del estado colonial, en todo caso su peso predominante en las prácticas científicas locales las ponía en riesgo de separarse de las redes internacionales de investigación y sanción del conocimiento. La soledad del erudito criollo hacía más meritorio su talento, pero al mismo tiempo era un obstáculo para desplegar a fondo la creatividad de manera razonable. La invención de Caldas del hipsómetro es, tal vez, el ejemplo más representativo. El modelo lineal empleado por Caldas para calcular las alturas de los lugares por medio de las correlaciones entre medidas del termómetro y del barómetro era anacrónico con respecto al modelo exponencial europeo (básicamente de Saussure y De Luc) que Humboldt ya conocía cuando Caldas le explicó el suyo en el encuentro de Quito en noviembre de 1801 (Arboleda, 2007).

La segunda característica del criollismo científico, según Humboldt, era un cierto optimismo telúrico que movía a los criollos a encontrar razones propias para la realización del saber en las condiciones del espacio geo-cultural local. En el contexto de la cita anterior, Humboldt se refiere a la gran influencia sobre "los americanos de Quito a Popayán" de las obras de Bouguer y La Condamine con los resultados de la expedición al Ecuador para medir un grado de meridiano y validar la teoría newtoniana de la figura de la tierra. Humboldt estaba impresionado por la manera como los criollos adecuaban e incorporaban las observaciones científicas de los misioneros europeos en la selección e investigación de problemas sobre el territorio de la Nueva Granada. En su paso por Popayán (si no con anterioridad en sus charlas con Mutis en Santafé), Humboldt recibió testimonios sobre las motivaciones, modalidades y resultados de los trabajos astronómicos de Caldas, en particular la fundamentación de sus actividades de reconocimiento científico del territorio en dos obras con las que estaba a todas luces familiarizado y a las cuales confería mucha autoridad y confianza: las Observaciones astronómicas (Juan \& Ulloa, 1748), y la Figure de la Terre (Bouguer, 1744). Sus lecturas de las Observaciones fueron decisivas, por ejemplo, para que Caldas pudiera construir el cuadrante de círculo con el cual identificó el anillo de Saturno, los satélites de Júpiter y finalmente determinó la posición de Popayán.

En otro elogio de Caldas incluido en su Diario de 1810 (citado en: (Bateman, 1978; p. 85)), Humboldt retoma estos testimonios y destaca que el sentimiento telúrico o pulsión de conocimiento basado en la explicación de las propiedades del espacio geográfico local fue un motor de creatividad en Caldas. Ello le permitió, incluso, ir más allá de las descripciones 
incompletas de las obras de este género que se esmeró en consultar. Refiere Humboldt la admirable competencia de Caldas en la apropiación del estado del arte en el conocimiento astronómico para la determinación de la latitud y longitud de las alturas de ciertos lugares de la Nueva Granada empleando para ello instrumentos construidos por él mismo:

“El señor Caldas, de quien no se elogiará bastante el celo por el progreso de la geografía (...) observó la latitud de Gigante con instrumentos construidos por él mismo, a saber un cuarto de círculo de 16 pulgadas, y un gnomon de cinco pies...Para fijar la longitud, el señor Caldas observó con cuidado extremo, el eclipse de luna del 3 de diciembre de 1797, se sirvió para esto de un anteojo acromático de treinta pulgadas y de un buen reloj."

Humboldt hace mención de la circunstancia de que Caldas haya vinculado, con las mediciones de Gigante, la observación del eclipse total de luna del 3 al 4 de diciembre de 1797, un acontecimiento científico al cual los astrónomos europeos le habían conferido una especial importancia. Pero en las condiciones locales, esta observación tenía una significación adicional en términos geográficos, socioeconómicos y en la propia posición profesional de Caldas. En lo geográfico, era un medio para establecer la longitud de Gigante y poder determinar, a partir de allí, otras latitudes más importantes por medio de triangulaciones. Los cálculos de Gigante tenían igualmente una connotación social: hacían parte del trabajo de levantamiento de la carta de la provincia de Timaná, con el cual debía, finalmente, resolverse el contencioso de límites entre los cabildos de La Plata y Timaná. Era claro para Caldas y los cabildantes que tales disputas fronterizas no podían zanjarse consultando el género ya anacrónico de mapas descriptivos como el elaborado por Piedrahita en el siglo XVII.

En cuanto al interés personal de estas mediciones, hay que recordar que para Caldas y otros miembros de la élite de científicos criollos, la apropiación social del conocimiento astronómico y geográfico apuntaban al mismo tiempo a la búsqueda de legitimidad con respecto al Estado y a apuntalar sus roles en la categoría socio profesional emergente. El contrato para elaborar este mapa le brindaba la primera oportunidad de vender sus servicios profesionales como geógrafo a las administraciones locales, en una carrera que iba a conducirlo, a la muerte de Mutis, a ocupar la dirección del Observatorio Astronómico de Santafé. La figura de Caldas, el astrónomo cuyos méritos intelectuales y profesionales fueron elogiados por Humboldt, no podría comprenderse en su real dimensión histórica, si no se tuvieran en cuenta el propósito que caracterizó su práctica científica: ser útil en la ciencia y con la ciencia al doble proyecto social de la élite criolla (Arboleda, 1994). Esta idea se encuentra presente en varios de sus escritos. Por ejemplo, en el siguiente extracto del prefacio del almanaque de 1811, año I de la independencia de la Nueva Granada (Caldas, 1996):

“Observar el cielo por observarlo sería una ocupación honesta, pero no pasaría de ser una curiosidad estéril que llenase los momentos del hombre ocioso y acomodado. Este observador sería inútil, y la Patria lo miraría como un consumidor de quien no esperaba nada. Nosotros no queremos representar este papel en la sociedad: queremos que nuestros trabajos astronómicos mejoren nuestra geografía, nuestros caminos y nuestro comercio.

\section{Bibliografía}

Arboleda, L.C. (1994). Ciencia y nacionalismo en la Nueva Granada en los albores de la revolución de independencia. En L. C. Arboleda \& S. Díaz-Piedrahita (Eds.), Francisco Joseph de Caldas y Thenorio. 1768-1816 (pp. 139-145). Bogotá: Molinos-Velásquez editores.

Arboleda, L. C. (2007). Caldas y la Matematización de la Naturaleza. La querella con Humboldt sobre el hipsómetro. En A. Escovar \& M. S. Reyna (Eds.), Popayán: 470 años de historia y patrimonio (pp. 119-135). Bogotá: Letrarte Editores.

Bateman, A. (1978). Francisco José de Caldas. El hombre y el sabio. Su vida-Su obra. Cali: Biblioteca Banco Popular.

Bouguer, P. (1749). La figure de la terre, déterminée par les observations de Messieurs Bouguer \& de la Condamine. Paris: Jombert.

Caldas, F. J. (1942). Semanario del Nuevo Reino de Granada. 3 vols. Biblioteca Popular de Cultura Colombiana. Bogotá: editorial Kelly.

Caldas, F.J. (1978). Cartas de Caldas. Bogotá: Academia Colombiana de Ciencias Exactas, Físicas y Naturales.

Caldas, F. J. (1996). Obras completas de Francisco José de Caldas. Bogotá: Universidad Nacional de Colombia.

Hernández de Alba, G. (1983). Archivo epistolar del sabio naturalista José Celestino Mutis. Bogotá: Instituto de Cultura Hispánica.

Humboldt, A. von (1982). Alexander von Humboldt en Colombia. Extractos de sus diarios. Auswahl aus seinen Tagebuchern. Edición bilingüe. Academia Colombiana de Ciencias Exactas, Físicas y Naturales - Academia de Ciencias de la República Democrática Alemana. Bogotá: Publicismo ediciones.

Juan J. \& Ulloa A. de (1748). Observaciones astronómicas y physicas hechas por orden de su magestad en los reynos del Perú de las cuales se deduce la figura y magnitud de la tierra y se aplica a la navegación. Madrid: Juan de Zúñiga.

\section{Luis Carlos Arboleda}

Coordinador

Grupo de Historia y Filosofía de la Ciencia

Académico correspondiente

Academia Colombiana de Ciencias Exactas, Físicas y Naturales 